\title{
Infraestrutura de saneamento básico e incidência de doenças associadas: uma análise comparativa entre Belo Horizonte e Ribeirão das Neves - Minas Gerais
}

\author{
Sanitation infrastruture and associeted diseases: a comparative analysis between \\ Belo Horizonte and Ribeirão das Neves - Minas Gerais
}

Grace Kelly Amaral Ventura

Geógrafa, UFMG

Técnico em Hidrologia

Serviço Geológico do Brasil - CPRM

grace.ventura@cprm.gov.br

Frederico Azevedo Lopes

Geógrafo, Doutor em Análise Ambiental

Professor do Departamento de Geografia

Programa de Pós-Graduação em Análise e Modelagem de Sistemas Ambientais

Universidade Federal de Minas Gerais

fredericolopes@ufmg.br

\begin{abstract}
Resumo
Apesar da reconhecida importância dos serviços de saneamento básico sobre os padrões e morbidade mortalidade da população, ainda pode-se observar uma disparidade entre as diversas regiões e localidades no Brasil, especialmente em relação aos índices de tratamento de esgotos. Neste contexto, este trabalho discute a importância da relação entre saneamento e saúde através do estudo da infraestrutura de saneamento básico e a incidência de doenças associadas, nas cidades de Belo Horizonte e Ribeirão das Neves. Para tanto, foram feitas análises dos índices de atendimento da população por serviços de saneamento básico, bem como das taxas de internações por leptospirose, cólera e doenças diarreicas. Os resultados obtidos revelaram que apesar de fazerem parte da mesma Região Metropolitana, serem próximas e conurbadas, as duas cidades estudadas apresentam relevantes diferenças com relação à oferta de serviços de saneamento básico, especialmente quanto ao tratamento de esgotos e destinação de resíduos sólidos. Belo Horizonte encontra-se bem próxima da universalização da oferta de serviços, enquanto Ribeirão das Neves não trata nem 10\% de seus esgotos. No entanto, em relação aos casos de internações pelas doenças estudadas, os dois municípios apresentam algumas situações similares, o que levanta a discussão de outros fatores que possam interferir na saúde pública, como importância da educação sanitária para efetivo controle de doenças infecciosas.
\end{abstract}

Palavras-chave: Saúde pública, saneamento básico, leptospirose, cólera, diarreias.

\begin{abstract}
Despite of the recognized importance of sanitation services over patterns of population morbidity and mortality, it is still possible to regard a discrepancy between regions and localities in Brazil. Thus, this work discusses the importance of the relationship between sanitation and health through the study of basic sanitation infrastructure and the incidence of associated diseases, in the cities of Belo Horizonte and Ribeirão das Neves. For this purpose, analyzes were made of the population service rates for basic sanitation services, as well as the rates of hospitalization for leptospirosis, cholera and diarrhea. The results revealed that despite being part of the same metropolitan area, both cities studied showed significant differences in relation to the provision of basic sanitation services, particularly related to sewage treatment and disposal of solid waste. Belo Horizonte is very close to the universal service provision, while Ribeirao das Neves does not treat even $10 \%$ of their sewage. However, in
\end{abstract}


the cases of hospitalizations for the studied diseases, both municipalities have some similar situations, which raises the discussion of other factors that may affect public health, such as importance of health education for effective control of infectious diseases.

Keywords: public health, sanitation, leptospirosis, cholera, diarrhea.

\section{INTRODUÇÃO}

Um dos principais desafios da gestão pública, nas esferas nacional, estadual e municipal é a melhoria do sistema público de saúde. Nesse contexto, ações que visem à prevenção de doenças podem contribuir significativamente para diminuição dos gastos com tratamentos, tornando possível maior investimento em aprimoramento do sistema, refletindo em melhores condições de vida à população.

De acordo com a Fundação Nacional da Saúde (FUNASA), para cada R\$ 1 investido em saneamento são economizados R $\$ 4$ em gastos com a saúde (FUNASA, 2014). Esse dado expressa a grande influência da salubridade ambiental na situação de saúde de uma determinada população, além de evidenciar que para uma gestão adequada das ações públicas nesse sentido é indispensável considerar a importância do investimento em melhoria das condições sanitárias do ambiente.

No Brasil, embora o saneamento básico seja considerado pela lei que rege as ações de promoção, proteção e recuperação da saúde em todo território nacional, como uma das condicionantes e determinantes da saúde (BRASIL; 1990 art. $3^{\circ}$ ), ainda existem 34 milhões de brasileiros sem acesso a água encanada e 103 milhões de pessoas não estão conectadas às redes de esgoto (SNIS, 2012). Apesar dos crescentes investimentos em infraestrutura sanitária nas últimas décadas, as doenças relacionadas ao saneamento ambiental inadequado ainda são a sexta maior causa de morte no país (FUNASA, 2010).

Além disso, há uma grande desigualdade na situação de saneamento básico entre as regiões brasileiras, e entre municípios com diferentes receitas. O retrato brasileiro assusta em função de tamanhas disparidades observadas, onde coexistem cidades que apresentam taxa de tratamento do esgoto coletado superior a 93\% (Rio de Janeiro e São Paulo) e outras em que essa taxa é de apenas 5,5\% (Macapá) (ONU, 2013).

Conforme a Organização Pan-Americana da Saúde (OPAS), o acesso aos serviços de saneamento decresce da população urbana para a rural e dos municípios de maior população para os de menor. A mesma situação pode ser visualizada nas áreas urbanas, onde a cobertura decai do centro para a periferia, isto é, há um decréscimo desses serviços das classes mais ricas para as mais pobres (OPAS, 1998). 
Entretanto, no caso do Brasil, a "metropolização" não foi acompanhada, em níveis adequados, pelo atendimento da população urbana por serviços de distribuição de água, coleta e tratamento de esgotos e resíduos sólidos, fator decisivo para o aumento das taxas de poluição da água e proliferação de doenças de transmissão hídrica como a diarreia. Com as deficiências no setor de saneamento básico, os planos e projetos de controle e/ou combate à degradação ambiental, principalmente em relação à água, tendem a tornar-se pouco eficazes (LOPES et al., 2003). Neste sentido, a população mais carente dos centros urbanos é condicionada, por sua situação econômica, a ocuparem áreas de risco, além de não terem acesso aos serviços básicos de saneamento, tornam-se vulneráveis às doenças de veiculação hídrica, especialmente as crianças (EHP, 1996; ZUCARELLI et al., 2010).

Diante desse cenário, fica evidente a importância da realização de estudos que busquem diagnosticar a ocorrência de agravos à saúde que podem ser evitados com adequada infraestrutura em saneamento básico. E que, além disso, trabalhem na escala local, visto que estudos regionais fazem uma generalização dos dados que acaba por mascarar as condições de determinada localidade, fazendo com que as dicotomias se perpetuem.

Desse modo, este trabalho tem como objetivo analisar a relação entre a infraestrutura de saneamento básico e a incidência de doenças associadas entre 2008 e 2013, além de seus efeitos sobre o Sistema Único de Saúde- SUS em Belo Horizonte e em Ribeirão das Neves ambas pertencentes a Região Metropolitana de Belo Horizonte - RMBH, buscando além do diagnóstico da situação de cada município, fazer uma análise comparativa entre eles.

\section{MATERIAL E MÉTODOS}

Para analisar a situação da infraestrutura de saneamento foram extraídos dados do Sistema Nacional de Informações sobre Saneamento- SNIS. O sistema é administrado pelo Governo Federal no âmbito da Secretaria Nacional de Saneamento Ambiental (SNSA) do Ministério das Cidades (MCID). O SNIS disponibiliza indicadores já calculados com base nos dados fornecidos pelos próprios prestadores de serviços de saneamento. Já os dados sobre manejo de águas pluviais, não são fornecidos pelo sistema. Portanto, foi feita uma caracterização da drenagem pluvial nos municípios, através de informações fornecidas pelos diagnósticos do saneamento básico feitos pelo plano municipal de saneamento básico de Belo Horizonte e pelo Plano Diretor de Ribeirão das Neves.

Para definição da série histórica dos dados analisados nesse trabalho, considerou-se principalmente a evolução na qualidade dos dados desagregados do SNIS, considerando o período compreendido entre 2008 a 2013. O referido período de análise foi selecionado em função da promulgação da Política Nacional do Saneamento Básico em 2007 (Lei 11.445/2007), que passou a 
ser considerado um divisor de águas para o setor, fomentando novos investimentos e instrumentos de gestão inovadores para o país.

A incidência de doenças associadas ao saneamento inadequado foi diagnosticada através da análise de dados extraídos dos Sistemas de Informação em Saúde, provenientes do Departamento de Informática do SUS - DATASUS. O departamento disponibiliza informações que podem servir para subsidiar análises objetivas da situação sanitária, tomadas de decisão baseadas em evidências e elaboração de programas de ações de saúde. Os indicadores de saúde foram calculados utilizando-se os dados do DATASUS e os dados de população extraídos do Instituto Brasileiro de Geografia e Estatística-IBGE.

\section{RESULTADOS E DISCUSSÕES}

Quanto ao atendimento da população por infraestrutura de abastecimento de água, os dados coletados apontaram que Belo Horizonte já alcançou a universalização do acesso e Ribeirão das Neves está bem próximo de atender a toda sua população, com um índice de atendimento de 99,27\% como pode ser observado no Gráfico 1.

Gráfico 1 - Índice de Atendimento Total de Água 2008 a 2013.

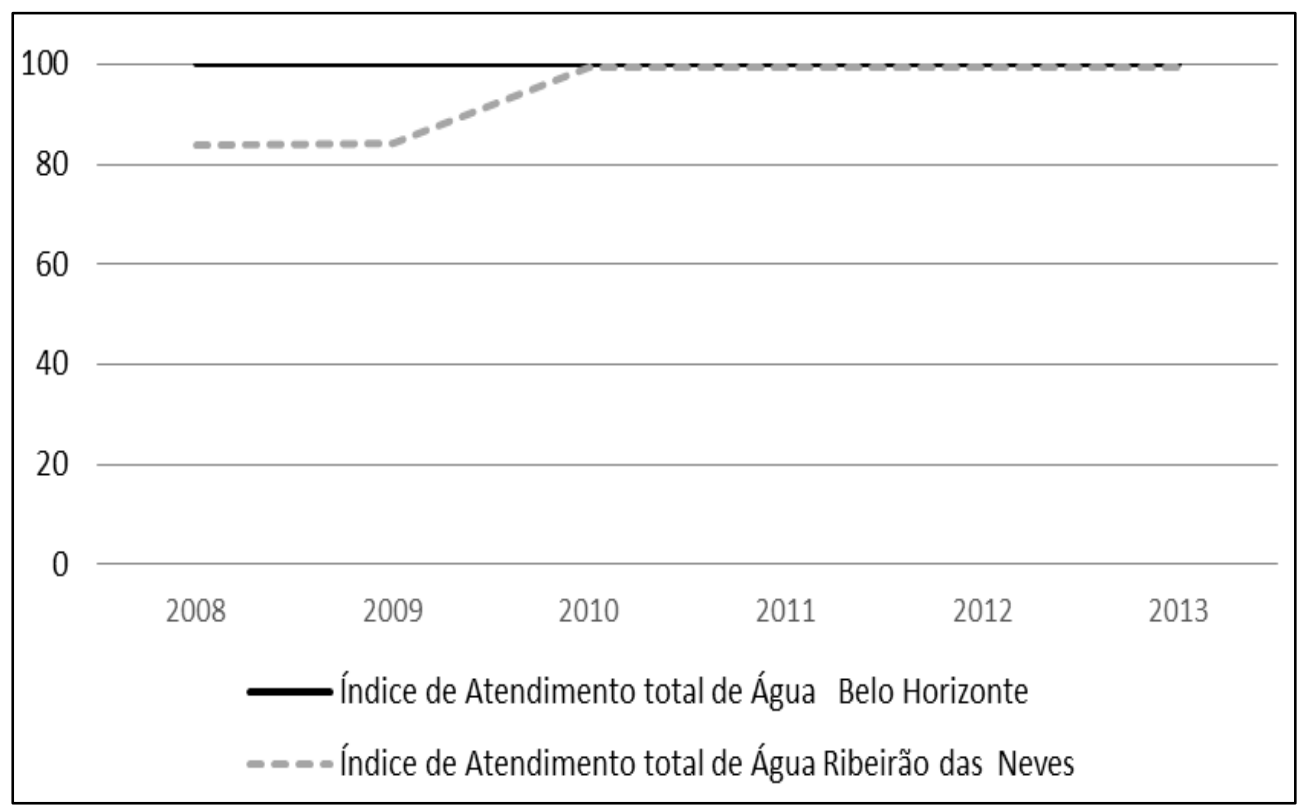

Em se tratando de esgotamento ${ }^{1}$ sanitário enquanto Belo Horizonte já possui toda sua população atendida, Ribeirão das Neves atende a 88,53\% da sua população. Em 2008 a capital

${ }^{1}$ Constituído pelas atividades, infraestruturas e instalações operacionais de coleta, transporte, tratamento e disposição final adequados dos esgotos sanitários, desde as ligações prediais até o seu lançamento final no meio ambiente (BRASIL, 2007). 
apresentava índice de $97,63 \%$, atingindo os $100 \%$ de atendimento de sua população em 2009, este índice foi mantido até o final do período analisado. Já Ribeirão das Neves apresentava em 2008 um índice de apenas 53,34 \% de sua população atendida por serviços de esgotamento sanitário, alcançando um crescimento de cerca de $35 \%$ no período analisado (Gráfico 2).

Gráfico 2 - Índice de atendimento total de esgotos 2008-2013

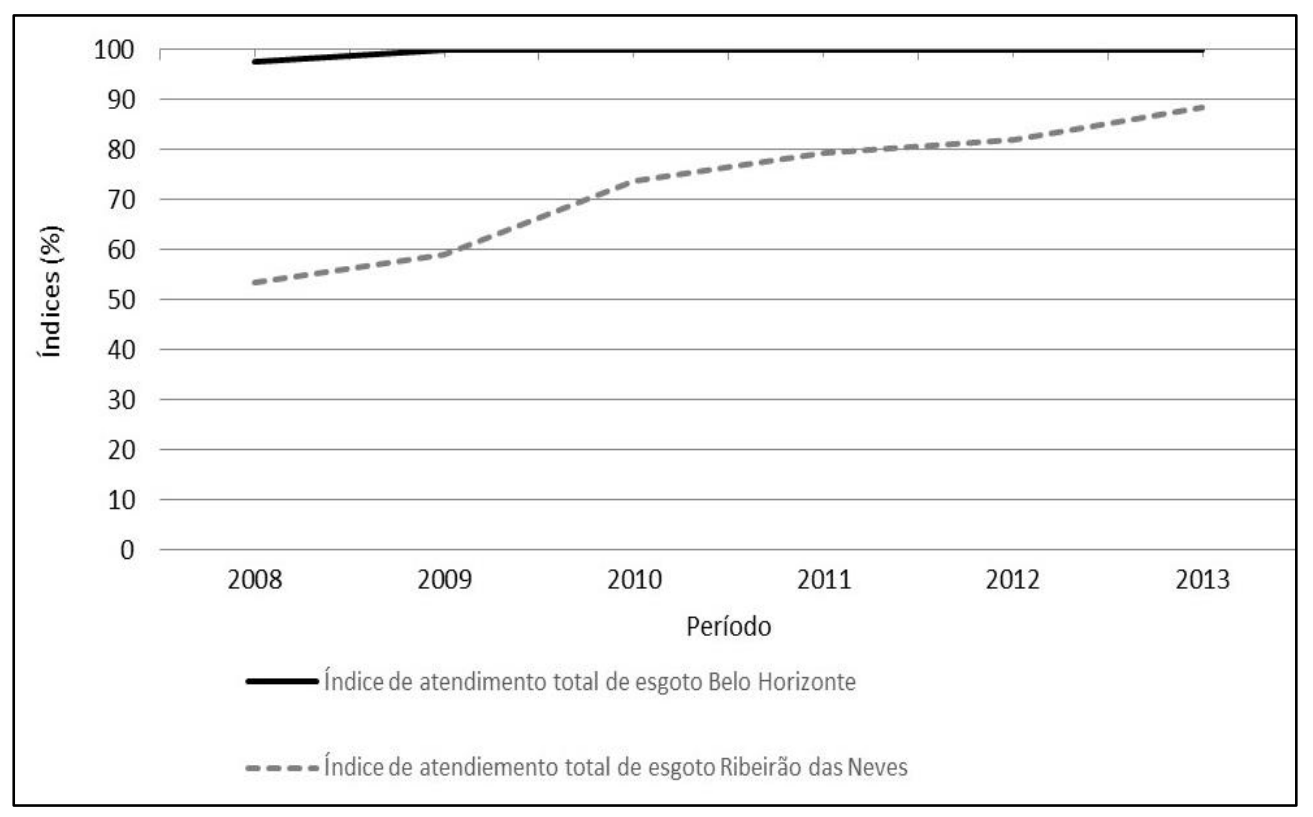

No entanto, quando se fala em tratamento de esgotos, os índices de atendimento são bem menos satisfatórios. Enquanto Belo Horizonte apresentou índice de tratamento de esgotos de 89,32\% em 2013, atingindo um crescimento de cerca de $10 \%$ entre 2008 e 2013, Ribeirão das Neves trata menos de $10 \%$, de seus esgotos, apresentando crescimento do índice de tratamento de apenas 0,74\% em todo período analisado (Gráfico 3).

Cabe ressaltar que além da cobertura da infraestrutura, a qualidade dos serviços de abastecimento de água e esgotamento sanitário são essenciais, uma vez que essas duas variáveis influenciam os padrões de morbidade e de mortalidade de uma população (LIBÂNIO et al., 2005; CATAPRETA; HELLER, 1999; COSTA et al, 2005; QUEIROZ et al., 2009; CALDEIRA et al., 2009). Deste modo, não basta apenas à cobertura por serviços. Os mesmos devem ser constantemente monitorados e avaliados em relação à sua eficácia.

Em relação à limpeza urbana e manejo de resíduos sólidos ${ }^{2}$, a capital apresentou índice de $96,45 \%$ de sua população atendida, com crescimento de apenas $1,45 \%$ desde o início do período

\footnotetext{
${ }^{2}$ Conjunto de atividades, infraestruturas e instalações operacionais de coleta, transporte, transbordo, tratamento e destino final do lixo doméstico e do lixo originário da varrição e limpeza de logradouros e vias públicas (BRASIL, 2007)
} 
analisado. Já Ribeirão das Neves apresentou taxa de cobertura de 100\% nos anos de 2012 e 2013, não sendo possível analisar evolução da taxa, já que só existem dados disponíveis a partir de 2012.

Gráfico 3 - Índice de tratamento de esgotos 2008 -2013

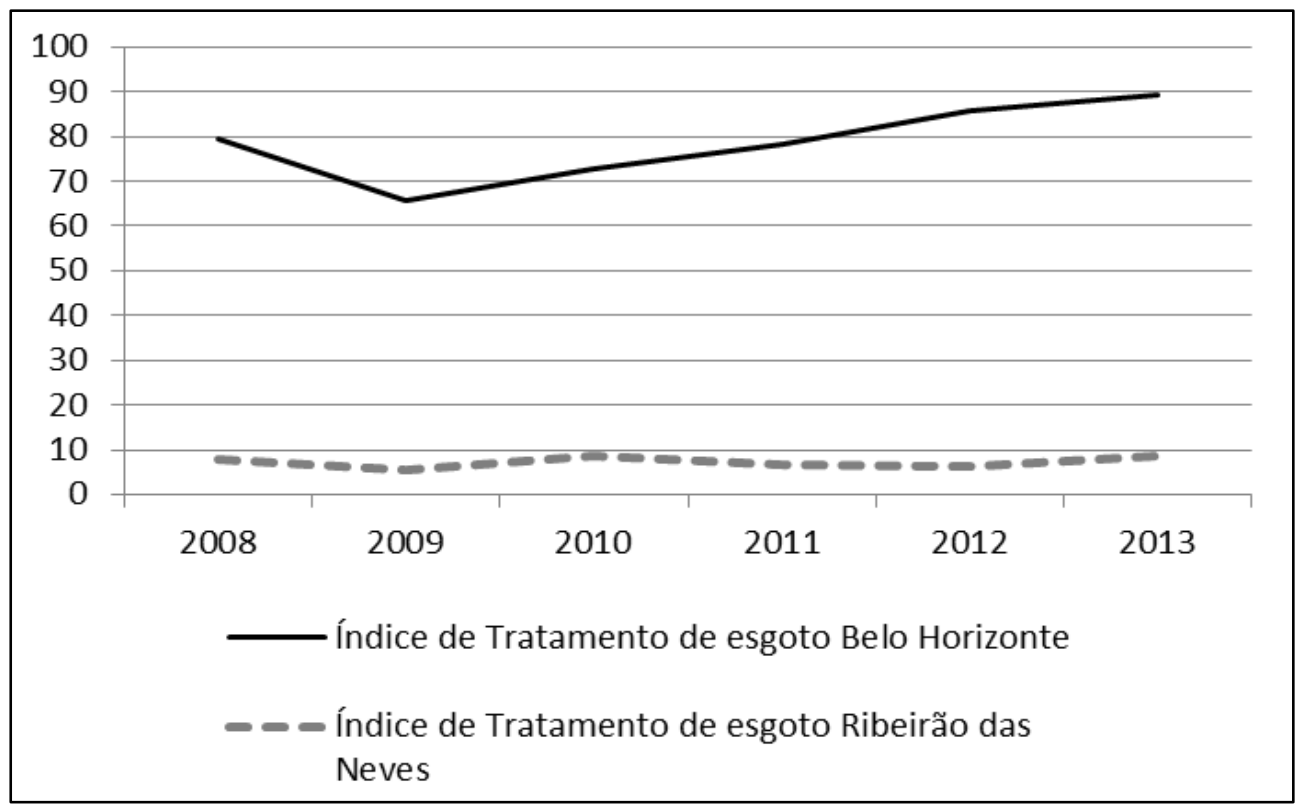

Belo Horizonte faz a destinação final adequada de seus resíduos. Possui três estações de tratamento de recicláveis além de aterro para resíduos inertes e aterro sanitário. Atualmente, o aterro sanitário do município encontra-se desativado e, portanto, a capital envia resíduos para CTR/Macaúbas (CTRS/BR-040), aterro sanitário localizado no Município de Sabará (SNIS, 2013). Já Ribeirão das Neves, destina seus resíduos de maneira precária, já que as únicas unidades de processamento que possui são dois aterros controlados, um deles operado por uma empresa privada e o outro pela prefeitura municipal.

Em relação à drenagem pluvial, conforme Belo Horizonte (2012), desde a fundação da capital mineira, foram registradas inundações decorrentes de sua urbanização sobre a rede hidrográfica natural. Dessa forma, novas ocorrências de inundações, repetidas a cada estação chuvosa e sempre de forma evolutiva, se deram devido ao avanço da urbanização e a consequente ocorrência de ocupações em áreas vulneráveis a tais eventos. Semelhante é a situação de Ribeirão das Neves, que de acordo com Ribeirão das Neves (2006) sofreu um processo de rápida expansão urbana que desconsiderou as margens de cursos d'água e o relevo natural do seu território, que possui, em muitos lugares, altas declividades. A cidade enfrenta ainda problemas devidos a falta de pavimentação de algumas vias, bem como da pavimentação executada sem os dispositivos de drenagem pluvial. 


\subsection{Perfil epidemiológico das doenças relacionadas à infraestrutura de saneamento}

\subsubsection{Leptospirose}

As maiores taxas de internações por leptospirose registradas em Belo Horizonte e Ribeirão das Neves foram de 0,67 em 2011, e de 0,99 a cada 100.000 pessoas em 2012, respectivamente. Cabe ressaltar que os dados utilizados somente consideram os pacientes que chegaram a fase mais aguda, ou seja, passíveis de internação (Gráfico 4).

Gráfico 4 - Taxa de Internação por leptospirose 2008-2013.

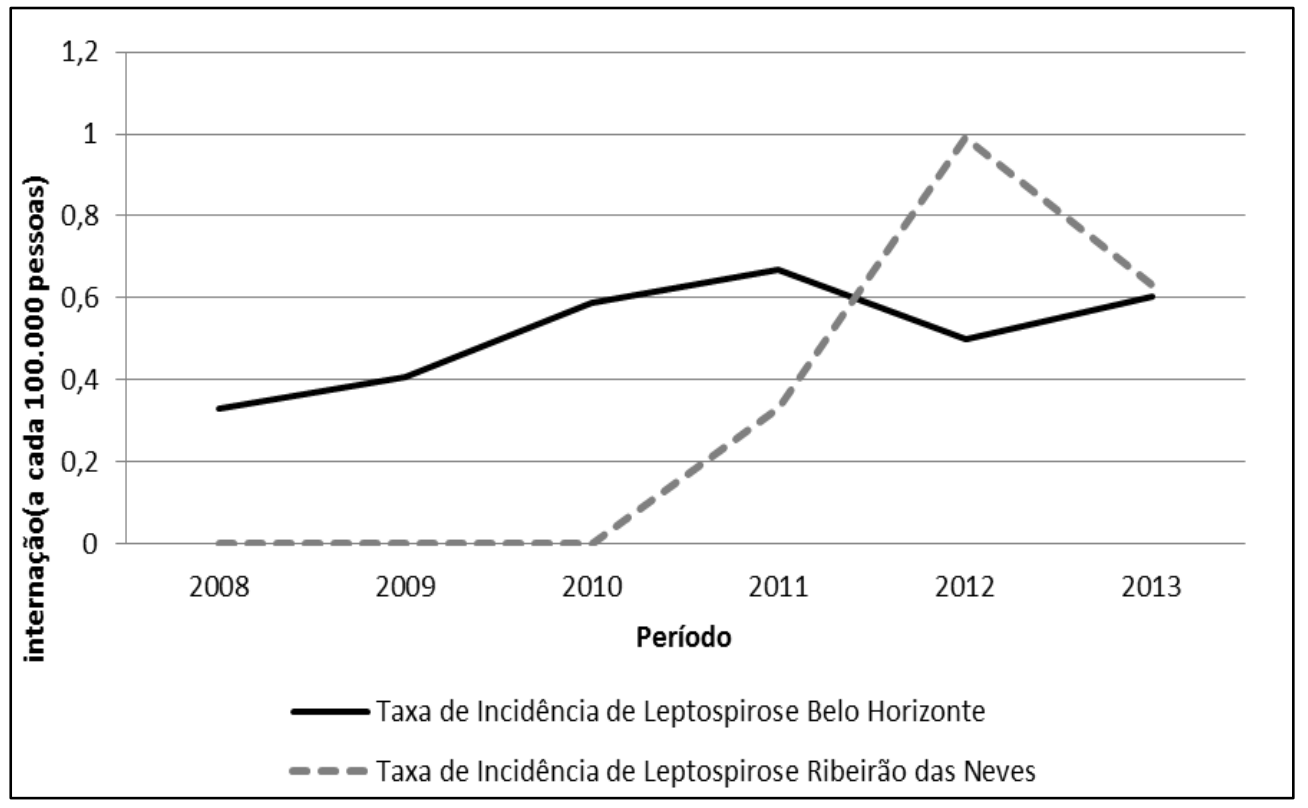

De acordo com o Ministério da Saúde (2014), apenas aproximadamente 15\% dos casos de Leptospirose evoluem para casos mais graves, o que indica que as taxas de internação registradas pelo DATASUS, podem representar um número de infectados bastante superior. Além disso, na fase chamada de precoce os sintomas são: instalação abrupta de febre, comumente acompanhada de cefaleia (dor de cabeça), mialgia (dores musculares), anorexia (falta de apetite), náuseas e vômitos, facilmente confundíveis com outras doenças febris (BRASIL, 2017). Essa fase corresponde a 85 a 90\% das formas clínicas, mas poucos casos são identificados e notificados nessa fase da doença, em decorrência das dificuldades inerentes ao diagnóstico clínico e à confirmação laboratorial.

O Coeficiente de letalidade da leptospirose no Brasil é de cerca de $10 \%$ dos infectados, podendo chegar a $40 \%$ nos casos mais graves. Em Ribeirão das Neves não foram registradas mortes pela doença no período analisado, enquanto que em Belo Horizonte foram registradas mortes nos anos de 2008, 2010 e 2013, com tendência de queda das taxas. A maior registrada foi em 2008, 
quando a cada 100.000 habitantes 25 morreram devido a doença. A menor taxa registrada foi em 2013 quando cerca de 7 pessoas a cada 100.000 morreram devido a leptospirose.

Segundo a Funasa (2010) a leptospirose é uma doença bacteriana aguda causada por microrganismos do gênero Leptospira presentes na urina de animais, com destaque para os ratos que são os principais reservatórios da doença. A forma mais comum de transmissão é através do contato direto ou indireto da pele com a urina de animais infectados. Nas áreas urbanas a infecção ocorre principalmente em situações de inundações ou alagamentos, já que a urina dos ratos, presente em esgotos e bueiros, mistura-se à enxurrada e à lama, favorecendo o contato das pessoas com a urina contaminada.

Apesar da falta de dados concretos, a caracterização da drenagem pluvial tanto em Belo Horizonte, quanto em Ribeirão das Neves aponta graves problemas, que geram reiterados episódios de inundações e alagamentos nos dois municípios. Isso pode explicar a ocorrência de Leptospirose tanto em Belo Horizonte quanto em Ribeirão das Neves. Por outro lado, os dois municípios possuem índices elevados de atendimento da população por coleta de resíduos sólidos, o que pode ser fator determinante para que não tenham ocorrido graves surtos da doença nos municípios.

\subsubsection{Cólera}

O Ministério da Saúde (2014) destaca que o país enfrentou em 1991 uma epidemia de cólera, especialmente nas regiões Norte e Nordeste, com incursões ocasionais nas demais regiões. Após o início da epidemia no país, no ano de 1993 foi registrado o maior número de infectados (mais de 60.000) e de óbitos (670). Desde então, o número de casos oscilou, com declínio gradativo até 2001, quando foram registrados 7 casos, procedentes dos estados do Ceará, Alagoas, Sergipe e Pernambuco.

Em 2008, 2009 e 2010 Belo Horizonte registrou casos de internação por cólera, sendo 18 nos 2 primeiros anos e 22 casos em 2010, com taxas de 0,74, 0,73 e 0,93 a cada 100.000 habitantes, respectivamente. Nos demais anos analisados as taxas apresentaram declínio acentuado até chegar a 0 em 2013. Em Ribeirão das Neves foram registradas taxas de 0,59, 0,86 e o maior número de internações também foi em 2010, 1,69 a cada 100.000 pessoas. Não foram registradas internações pela doença no município após 2010 (Gráfico 5).

O Vibrio cholerae é o agente etiológico da cólera, e é eliminado pelas fezes ou vômitos de pessoas infectadas, sintomáticas ou não e pode ser transmitido de forma indireta que é quando ocorre pela contaminação pessoa a pessoa, devido, principalmente, à elevada existência de assintomáticos (portadores sadios). Ou pela forma direta, que é a mais frequente e de maior incidência nos surtos, ocorrendo, principalmente, pela ingestão de água ou alimentos contaminados. Uma das ações 
prioritárias é o investimento público para melhoria da infraestrutura dos serviços de abastecimento de água para consumo humano, coleta e tratamento de esgotos e resíduos sólidos, no sentido de prover a população de condições adequadas de saneamento básico, contribuindo para a prevenção, controle e redução dos riscos e casos da doença (BRASIL, 2014).

Gráfico 5 - Taxas de internação por cólera 2008-2013.

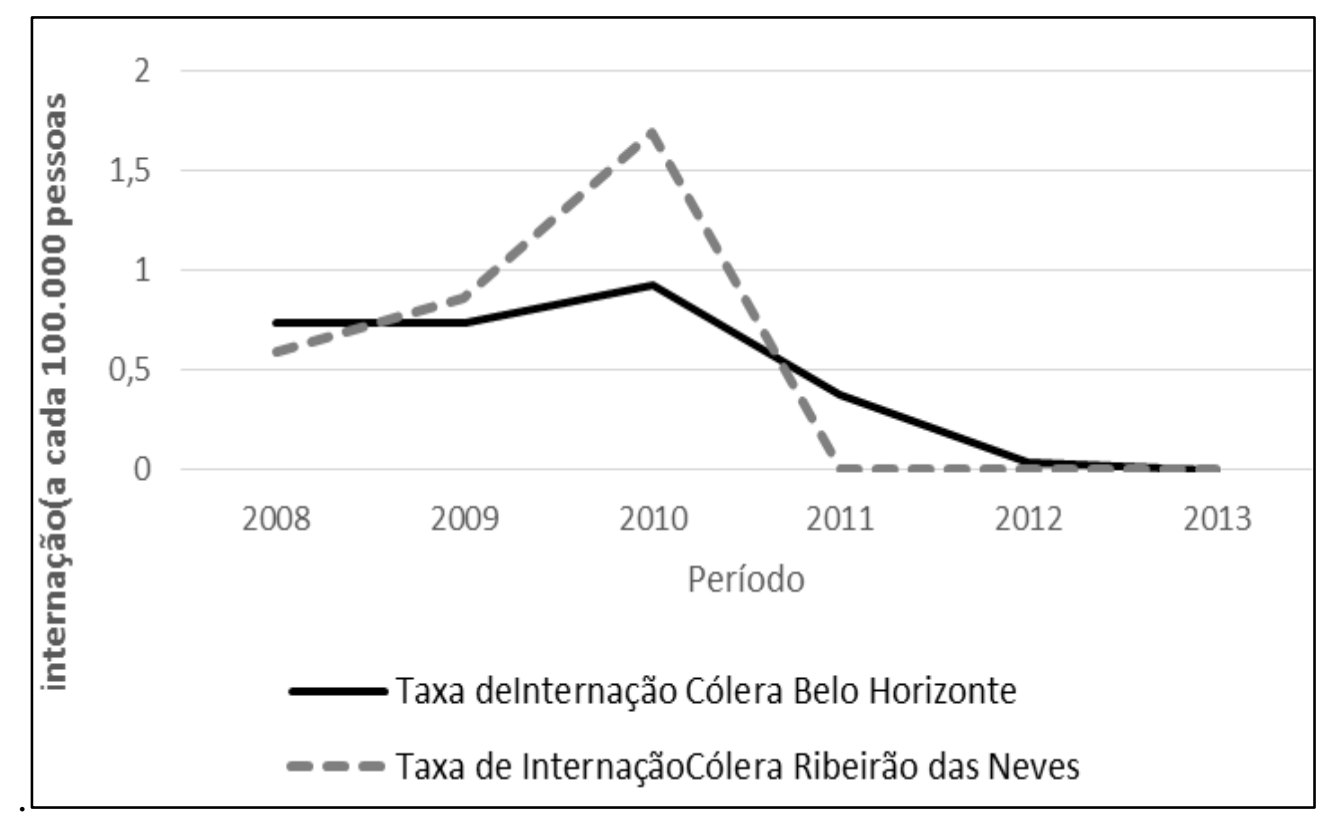

As manifestações clínicas da cólera variam desde infecções assintomáticas até casos graves com diarreia profusa. Os quadros leves e as infecções assintomáticas são mais frequentes do que as formas graves, portanto assim como nos casos de leptospirose, a subnotificação é possivelmente comum em casos de cólera. Os últimos óbitos pela doença ocorreram no ano 2000, quando foram registrados 20 óbitos (BRASIL, 2014). Nenhum dos municípios estudados registrou mortes por cólera, durante o período analisado.

Os municípios estudados possuem índices satisfatórios de atendimento da população por serviços de saneamento, especialmente no que diz respeito ao acesso a água potável, o que faz com que a cólera não seja um sério problema de saúde pública. Mas ainda assim, Belo Horizonte, que está bem próxima da universalização do acesso a serviços de saneamento em quase totalidade de seu território, ainda registra casos de cólera, o que ressalta a necessidade de ações de educação sanitária no município. 


\subsubsection{Diarreias}

O Ministério da Saúde (2014) destaca que a diarreia é a segunda causa de mortes em crianças menores de 5 anos em todo o mundo. Quase 1 em cada 5 mortes de crianças - cerca de 1,5 milhão por ano - é devido à diarreia. Portanto, as análises foram feitas separando-se as faixas etárias entre crianças de 0 a 4 anos que são sensivelmente mais afetadas e as demais faixas foram analisadas conjuntamente. Para calcular as taxas de incidência foram utilizadas também as contagens populacionais divididas em faixas etárias.

No Brasil, a diarreia é reconhecida como importante causa de morbimortalidade. Kronemberger (2013) revela que as piores taxas de internações por diarreia são registradas na cidade de Ananindeua-PA, com valores acima de 900 internações por diarreias a cada 100 mil habitantes, o município possui índice de atendimento de água de 26,91\% (INSTITUTO TRATA BRASIL, 2013). Como pode ser observado no gráfico 6, os dois municípios da RMBH estudados apresentaram expressivas taxas de internação, especialmente entre as crianças, porém baixas em comparação com municípios em que as taxas são alarmantes, como em Ananindeua - PA.

Gráfico 6 - Taxas de internação por diarreia 2008-2013.

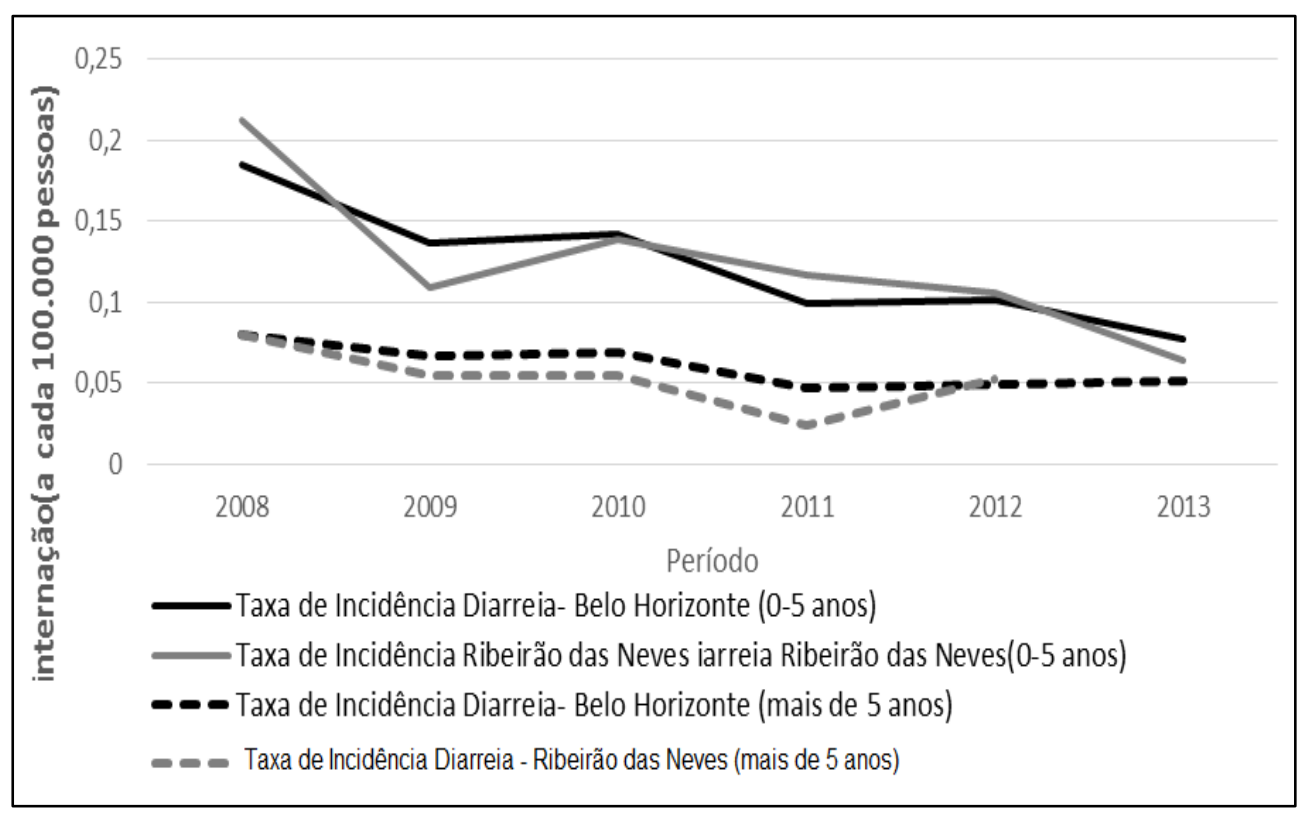

Em 2008 foram registradas maiores taxas do período, cerca de 269 e 215 internações a cada 100.000 crianças em Belo Horizonte e Ribeirão das Neves respectivamente. As taxas oscilaram entre o período com picos em 2010 e 2012. No final do período foram registradas as menores taxas em Belo Horizonte e Ribeirão das Neves 142 e 86 internações a cada 100.000 crianças respectivamente. 
$\mathrm{Na}$ análise das faixas etárias de 5 anos ou mais os dois municípios apresentaram taxas bem menores. Em 2008 ocorreu o maior número de internações, quando foram registrados cerca de 8 internados a cada 100. 000 habitantes tanto em Belo Horizonte como em Ribeirão das Neves. O número de internações oscilou durante o período, as menores taxas nas duas cidades foram registradas em 2011, quando em Belo Horizonte foram internados cerca de 5 a cada 100.000 habitantes, enquanto que em Ribeirão das Neves foram internadas cerca de 3 pessoas a cada 100.000 habitantes, como apresentado no gráfico 6.

De acordo com Ministério da Saúde (2014) os agentes etiológicos da diarreia são as bactérias e suas toxinas, vírus, parasitos e toxinas naturais. Sua transmissão pode ser direta - pessoa a pessoa (por exemplo, mãos contaminadas) e de animais para pessoas, ou indireta - ingestão de água e alimentos contaminados e contato com objetos contaminados (por exemplo, utensílios de cozinha, acessórios de banheiros, equipamentos hospitalares). As infecções por diarreia mantêm relação direta com as precárias condições de vida e saúde dos indivíduos, em consequência da falta de saneamento básico e desnutrição crônica, entre outros fatores. Do total de mortes por diarreias no mundo, $88 \%$ tem relação com condições de saneamento básico inadequado (OMS, 2009 apud Kronemberger, 2013).

Estudo feito por Kronemberger (2013), aponta relação direta entre os índices de atendimento da população por serviços de esgotamento sanitário, e taxas de infecção por diarreia. Isso explica os índices encontrados em Ribeirão das Neves, que possui cerca de $12 \%$ de sua população não atendida por serviços esgotamento sanitário, e principalmente possui baixíssimo índice de tratamento de esgotos. Já Belo Horizonte suscita discussão, pois apesar de o município possuir bons índices de cobertura de saneamento básico, o mesmo apresenta expressivas taxas de internações por diarreias, o que demonstra a necessidade de melhoria na qualidade dos serviços, bem como de educação sanitária.

Não foram registradas mortes de crianças por diarreia em nenhum dos municípios durante o período analisado. De acordo com o Instituto Trata Brasil (2014) a mortalidade infantil em Belo Horizonte caiu devido a melhorias no acesso e na qualidade da atenção básica à saúde. Nesses serviços, estão incluídos consultas, exames e acompanhamento feito pelas equipes de saúde da família nas residências dos pacientes. Além da melhoria das condições de vida, com o programa Bolsa Família, aumento do nível escolar e maior acesso a informação, além do saneamento básico e da água tratada que também contribuíram.

Por outro lado, entre os adultos foram registradas algumas mortes. As mais altas taxas de mortes por diarreia do período foram registradas em 2013 quando Belo Horizonte registrou taxa de 1,57 mortes a cada 100.000 pessoas, e Ribeirão das Neves apresentou taxa 6,67 mortes a cada 100.000 pessoas, ou seja, aproximadamente 4 vezes mais elevada. 
Apesar de não terem sido registrados casos de mortalidade infantil por diarreias no período analisado, o estudo desenvolvido por Barreto et al. (2007) conseguiu analisar e demonstrar os efeitos das intervenções sanitárias sobre a redução da diarréia em crianças menores de 3 anos. Ao comparar os resultados obtidos no período anterior e posterior ao término das mesmas, verificou uma redução geral de $22 \%$, chegando em até $43 \%$ nas áreas de maior risco. Desta forma, fica evidente que o investimento em saneamento traz benefícios em curto prazo para melhorias na saúde, com reflexos positivos sobre a redução de tratamentos médicos aos acometidos pela enfermidade, por exemplo, abrindo espaço para outros atendimentos prioritários dos centros de saúde.

Outro fator determinante para a redução e controle de infecções diarreicas se refere à educação sanitária, por meio da lavagem adequada das mãos e manuseio de alimentos. Neste contexto, ao destacar a importância do hábito de lavar as mãos para a redução de diarréias, Cairncross (2003) aponta que em países em desenvolvimento, a ocorrência de diarréias que causam sintomas de infecções respiratórias está relacionada, principalmente, à transmissão por via hídrica de bactérias e protozoários, dada a escassez e a precariedade dos sistemas de tratamento de água e esgoto. Além disso, a higienização das mãos pela população é um hábito que depende diretamente da facilidade de acesso à água tratada, que é precário em determinados locais periféricos dos centros urbanos e algumas áreas rurais.

\subsection{Impactos econômicos sobre o sistema único de saúde}

Quanto aos gastos hospitalares com os pacientes internados por leptospirose nota-se que somente em 2012, Ribeirão das Neves registrou gastos superiores aos de Belo Horizonte (Gráfico 7).

Além da taxa internações em Ribeirão das Neves ter sido mais elevada naquele ano, os casos registrados provavelmente foram de maior gravidade, já que a média de permanência dos pacientes foi de cerca de 17 dias, enquanto que em Belo Horizonte foi de aproximadamente 8 dias (Tabela 1).

Os gastos oscilaram durante o período, com expressivo aumento em Belo Horizonte no ano de 2013 numa comparação com o que foi gasto em 2008. A capital apresentou um gasto médio anual de aproximadamente $\mathrm{R} \$ 16.000$ reais com tratamento de internados por leptospirose, valor pouco expressivo se considerarmos o gasto total médio anual do município com internações que é de cerca $\mathrm{R} \$ 18.875 .420,63$ reais. Ao se considerar a taxa de gastos por habitantes, o valor se torna ainda mais inexpressivo, já que a média de gastos é de $\mathrm{R} \$ 389,97$ a cada 100.000 pessoas.

Quanto aos gastos hospitalares com pacientes internados por cólera, Belo Horizonte apresenta gastos superiores aos de Ribeirão das Neves, exceto em 2009 quando esta gastou R \$ 9.200, com taxa de gastos de $\mathrm{R} \$ 722$ reais a cada 100.000 habitantes na cidade. Além da elevação da taxa de internados 
como pode ser observado através do gráfico 11, Ribeirão das Neves registrou em 2009 uma elevação da média de dias de internação, como exposto no Gráfico 8.

Gráfico 7 - Taxa de gastos com leptospirose 2008-2013.

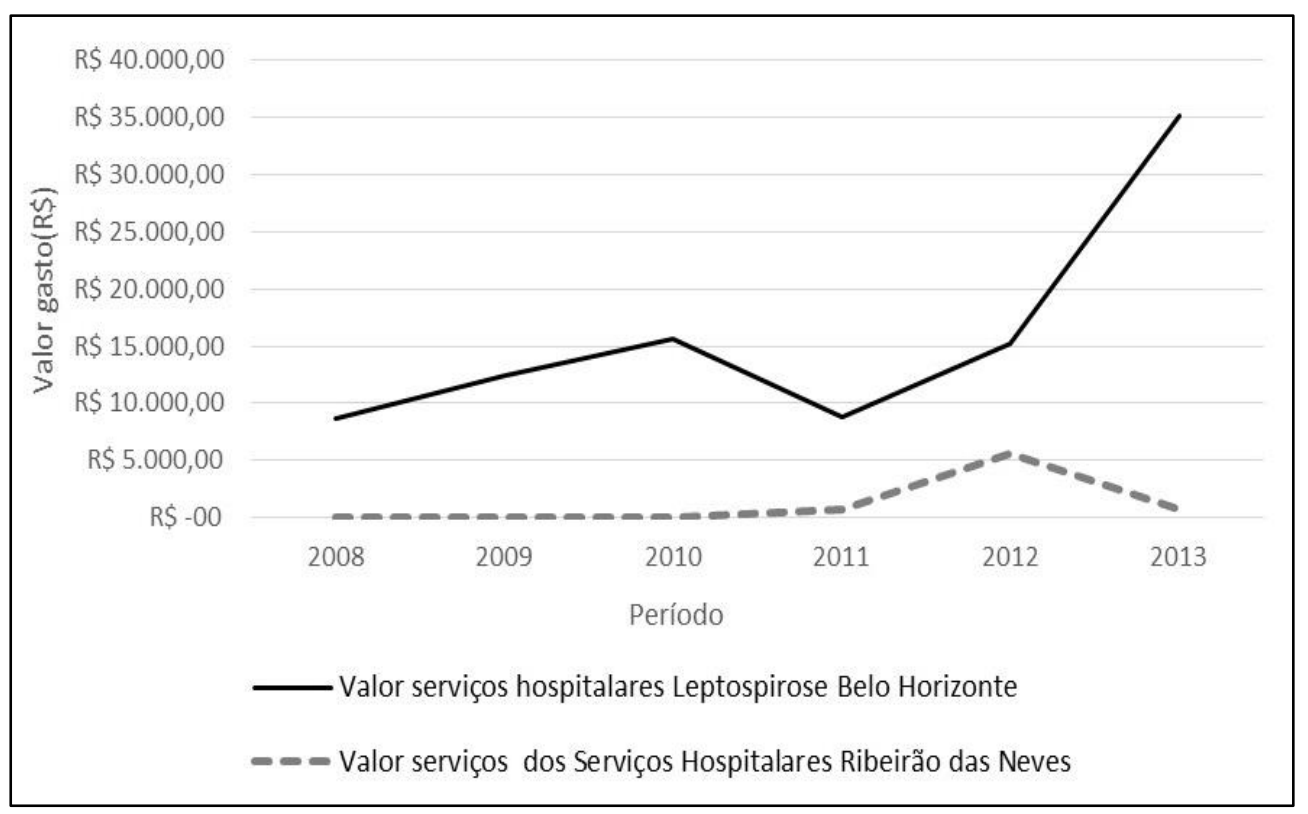

Tabela 1 - Permanência na Internação por leptospirose 2008-2013

\begin{tabular}{lcc}
\hline Período & Média permanência Belo Horizonte & Média permanência Ribeirão das Neves \\
\hline 2008 & 7,8 & 0 \\
2009 & 9,3 & 0 \\
2010 & 9,1 & 0 \\
2011 & 8,3 & 23 \\
2012 & 8,4 & 17,3 \\
2013 & 9,3 & 8 \\
\hline
\end{tabular}

Gráfico 8 - Taxa de gastos com cólera 2008-2013

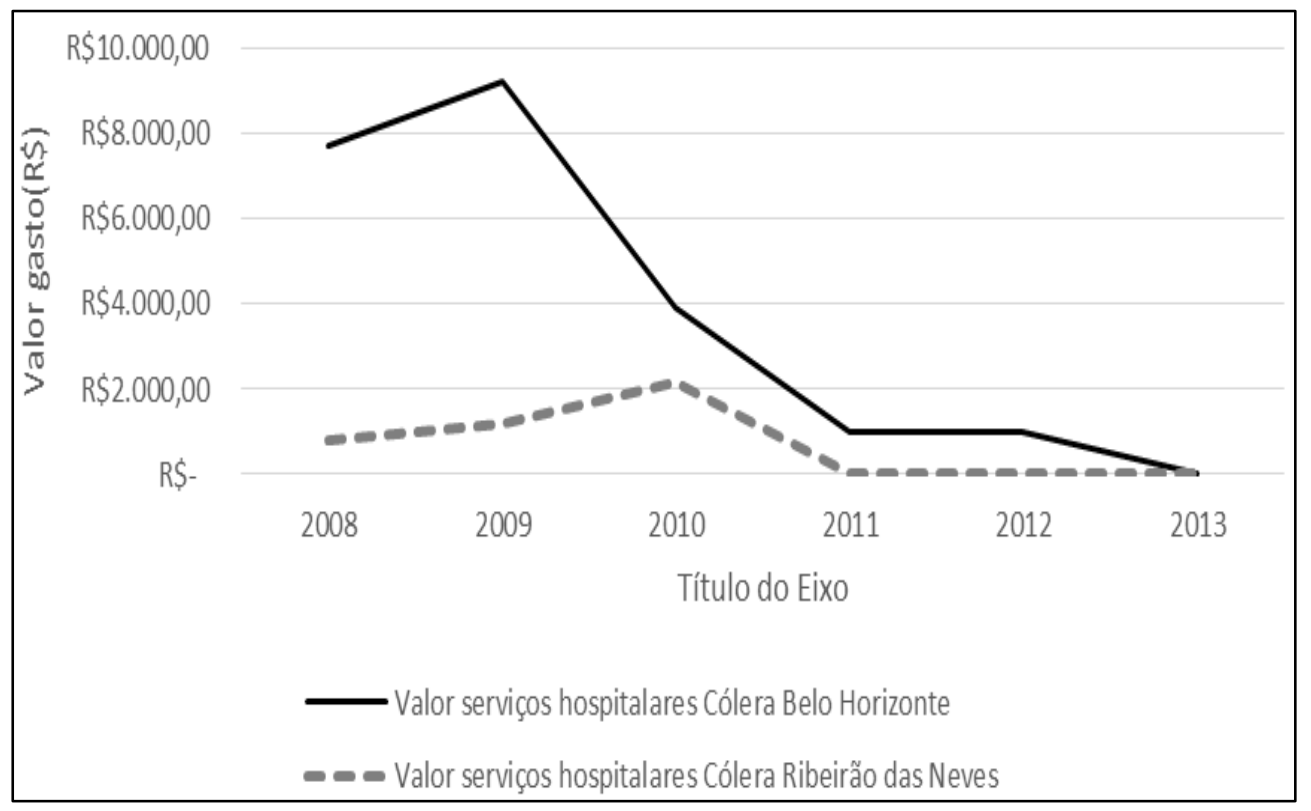


Em Belo Horizonte o pico de gastos foi em 2009, quando cerca de $\mathrm{R} \$ 375,00$ reais a cada 100.000 habitantes foram destinados a tratamento de pacientes com cólera. Nos demais anos houve uma tendência de queda nos valores gastos, devido à redução no número de pacientes internados, até que em 2013 nenhum dos municípios teve gastos com internações por cólera. Os gastos com a doença nos dois municípios chegam a ser ainda mais inexpressivos do que os gastos com leptospirose, se considerarmos o valor total gasto com internações nos dois municípios.

Com relação à média de permanência dos pacientes internados, nota-se que as internações em Belo Horizonte foram mais longas em quase todos os anos analisados, com exceção apenas de 2010, quando Ribeirão das Neves apresentou a maior média de tempo de internação de todo período (ver tabela 2), que ocasionou um salto nos valores gastos pelo município.

Tabela 2 - Permanência na Internação por cólera

\begin{tabular}{lcc}
\hline Período & Média permanência Belo Horizonte & Média permanência Ribeirão das Neves \\
\hline 2008 & 7,6 & 3 \\
2009 & 7,1 & 2,5 \\
2010 & 4,2 & 7 \\
2011 & 4,6 & 0 \\
2012 & 21 & 0 \\
2013 & 0 & 0 \\
\hline
\end{tabular}

Já os gastos com diarreia são bastante superiores aos registrados com internações por leptospirose e cólera representando em 2008 mais de $1 \%$ do valor gasto com internações hospitalares em Belo Horizonte e mais de 3\% dos gastos de Ribeirão das Neves. Nos demais anos analisados o gasto proporcional nos dois municípios apresentou queda até chegar 0,65\% em Belo Horizonte e $2 \%$ em Ribeirão das Neves em 2013. A taxa de gastos mais alta registrada em Belo Horizonte foi de R\$ 92.948 reais a cada 100.000 crianças de 0 a 4 anos, no ano de 2010. Já em Ribeirão das Neves o maior valor registrado foi de $\mathrm{R} \$ 67,582$ reais a cada 100.00 crianças em 2008. Já os gastos com internação de adultos por diarreia são bem inferiores, ainda assim são bastante superiores aos gastos gerais com internações tanto por leptospirose quanto por cólera, como pode ser observado através do gráfico 9.

Ao se analisar o tempo de internação, a diarreia (tabela 3) tem a menor média de dias de internação, em comparação com a cólera e a leptospirose, ainda assim possui maior impacto para saúde pública, tendo em vista o número de internações. Porém, vale destacar que a leptospirose tem um alto potencial de impacto já que o tempo de internação pela doença é mais elevado que o das demais. Em Ribeirão das Neves no ano de 2011, a média de internação dos infectados por leptospirose foi de 23 dias, o que pode gerar prejuízos tanto para a saúde pública devido à ocupação da rede, quanto para o doente que perde muitos dias de trabalho, estudo etc. 
Gráfico 9 - Taxa de Gastos com diarreia 2008-2013

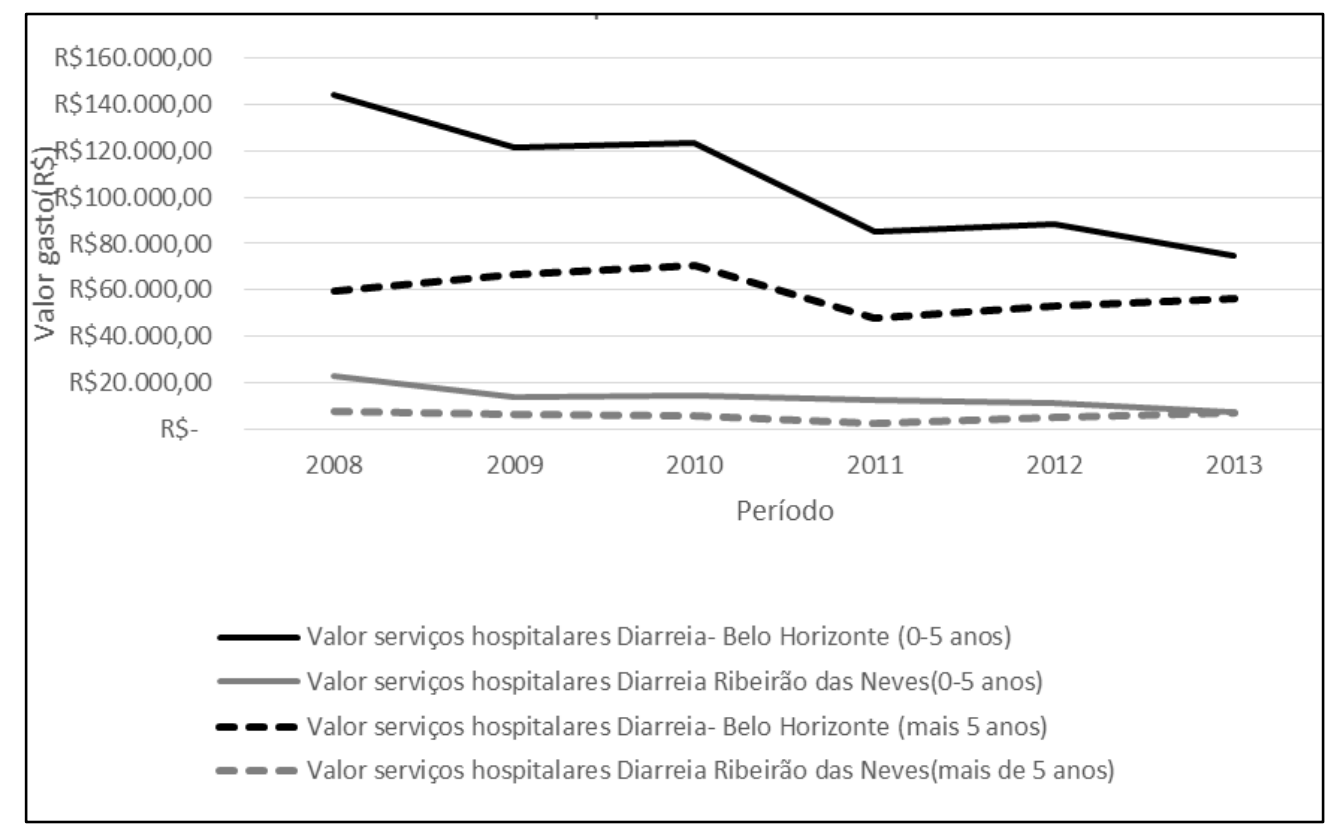

Tabela 3 - Permanência na internação por cólera

\begin{tabular}{lcc}
\hline Período & Média permanência Belo Horizonte & Média permanência Ribeirão das Neves \\
\hline 2008 & 3,2 & 3,3 \\
2009 & 4 & 5 \\
2010 & 3,9 & 3,7 \\
2011 & 4,8 & 2,9 \\
2012 & 4,6 & 3,4 \\
2013 & 4,4 & 4,4 \\
\hline
\end{tabular}

O gastos do SUS com internações por leptospirose, cólera e diarreias em Belo Horizonte e Ribeirão das Neves foi de $\mathrm{R} \$$ 1.237.525,27 de reais durante todo o período estudado ( 2008 a 2013), valor que provavelmente não gera impactos de elevada magnitude se considerarmos o montante total gasto em saúde nos dois municípios durante o período estudado que foi de R $129.981 .171,98$ de reais, mas que não deve ser desconsiderado já que é capaz de, por exemplo, cobrir, durante 1 mês, quase que a totalidade dos valores dos serviços hospitalares de um hospital de grande porte da capital, como o João XXXIII ${ }^{3}$, que atende não apenas a seus habitantes como também, de diversos municípios de seu entorno. Portanto, vale a pena a discussão de medidas para que esses impactos sejam ainda menores, tendo em vista que se tratam de doenças facilmente evitáveis.

\footnotetext{
${ }^{3}$ Valor dos serviços hospitalares do Hospital João XXIII, no mês de Dezembro de 20131.483.252,24 (DATASUS, 2014)
} 


\section{CONSIDERAÇÕES FINAIS}

Os dados referentes à oferta de saneamento básico nos municípios revelaram que Belo Horizonte está bem próxima da universalização do acesso aos serviços de saneamento, tendo como seu pior índice, o tratamento de esgotos. Por outro lado, Ribeirão das Neves, apesar da proximidade da capital, apresenta baixos índices, especialmente com relação ao tratamento de esgotos, que não atingiu $10 \%$ durante o período analisado. O que nos leva a refletir sobre a situação dos municípios pertencentes à $\mathrm{RMBH}$, com baixos índices de integração ao polo, que provavelmente devem apresentar índices de atendimento ainda mais discrepantes dos apresentados pela capital.

É importante destacar que apesar das diferenças na situação da infraestrutura de saneamento básico nos dois municípios, os índices de internação pelas doenças investigadas, especialmente com relação a diarreias, não apresentaram diferenças proporcionais às taxas de atendimento por serviços de saneamento. O que ressalta a importância do investimento em qualidade e ampliação dos mesmos, além do monitoramento dos mesmos.

Os dados de saúde revelaram ainda, que apesar de o país ter passado pelo processo de transição epidemiológica, a diarreia continua sendo uma importante causa de internação da população, não podendo ser desconsiderada quando do planejamento de medidas de melhoria da saúde pública.

A educação sanitária, apesar de fundamental para combate e controle de infecções de veiculação hídrica, apresenta-se pouco presente no Plano Municipal de Saneamento Básico de Belo Horizonte - PBH (2012), sendo pouco considerada no planejamento das ações de saneamento básico no município, tendo em vista sua presença em apenas algumas passagens do plano, especialmente em relação aos resíduos sólidos, ou controle de vetores de doenças. A importância de medidas educativas é citada, e de maneira bastante superficial, sem a devida importância que a questão merece. Além disso, medidas educativas que visem incentivar a higiene do indivíduo não são citadas e nenhum momento do plano.

Contudo, cabe destacar que foram analisadas apenas três doenças, entre as diversas outras que podem ser ocasionadas pela falta ou inadequação do saneamento básico. Deste modo, uma análise da totalidade das doenças pode revelar impactos econômicos ainda mais relevantes junto ao Sistema Único de Saúde - SUS. 


\section{REFERÊNCIAS}

BARRETO, M. et al. Effect of city-wide sanitation programme on reduction in rate of childhood diarrhea in northeast Brazil: assessment by two cohort studies. The Lancet. v.370, n. 10, p. 1622 1627, 2007.

BELO HORIZONTE, Prefeitura Municipal de Belo. Plano municipal de saneamento de belo horizonte - 2012/2015. Belo Horizonte: Secretaria Municipal de Obras e Infraestrutura, 2012.148p.

BRASIL. Lei $\mathbf{n}^{\circ}$ 8080, de 19 de setembro de 1990. Dispõe sobre as condições para a promoção, proteção e recuperação da saúde, a organização e o funcionamento dos serviços correspondentes e dá outras providências. Brasília, DF.

BRASIL. Decreto $\mathbf{n}^{\mathbf{0}} \mathbf{7 2 1 7}$, de 21 de junho de 2010. Regulamenta a Lei no 11.445, de 5 de janeiro de 2007, que estabelece diretrizes nacionais para o saneamento básico, e dá outras providências. Brasília, DF.

BRASIL. INSTITUTO BRASILEIRO DE GEOGRAFIA E ESTATÍSTICA- IBGE. Ministério do Planejamento Orçamento e Gestão. Atlas do Saneamento. Rio de Janeiro, 2011. 268 p.

BRASIL. Ministério da Saúde. Guia de Vigilância em Saúde / Ministério da Saúde, Secretaria de Vigilância em Saúde. Brasília: Ministério da Saúde, 2014. 812 p.

BRASIL. Ministério da Saúde. Organização Pan-Americana da Saúde. Avaliação de impacto na saúde das ações de saneamento: marco conceitual e estratégia metodológica. Organização PanAmericana da Saúde. Brasília: Ministério da Saúde, 2004.

BRASIL. Ministério da Saúde. Portal da Saúde. Informações técnicas: Leptospirose. Disponível em: <http://portalsaude.saude.gov.br/index.php/informacoes-tecnicas>. Acesso em: 03/08/2017.

CAIRNCROSS, S. Handwashing with soap - a new way to prevent ARIs? Tropical Medicine And International Health, London, v. 8, n. 8, p.1-3, ago. 2003.

CALDEIRA, M. M.; REZENDE, S.; HELLER, L. Estudo dos determinantes da coleta de resíduos sólidos urbanos em Minas Gerais. Eng. Sanit. Ambient.v.14, n.3, p.391-400, 2009.

CATAPRETA, C. A. A.; HELlER, L. Associação entre coleta de resíduos sólidos domiciliares e saúde, Belo Horizonte (MG), Brasil. Rev Panam Salud Publica. v.5, n.2, p. 88-96, 1999.

COSTA, S. S. et al. Indicadores epidemiológicos aplicáveis a estudos sobre a associação entre saneamento e saúde de base municipal. Eng. Sanit. Ambient., v.10, n.2, p.118-127, 2005.

DATASUS. Informações de saúde (TABNET). Epidemiológicas e morbidade. 2014. Departamento de informática - Ministério da Saúde. Disponível em: <http://www2.datasus. gov.br/DATASUS/index.php?area=0203. Acesso em: < 07 junho 2015.

ENVIRONMENTAL HEALTH PROJECT- EHP. Health \& environment in urban poor áreas: avoiding a crisis through prevention. EHP Capsule Report. n.1, 1996.

FUNDAÇÃO NACIONAL DA SAÚDE - FUNASA. Impactos na saúde e no sistema único de saúde decorrentes de agravos relacionados a um saneamento ambiental inadequado. Brasília: Fundação Nacional de Saúde, 2010. 246 p. 
INSTITUTO TRATA BRASIL. Ranking do saneamento instituto trata brasil resultados com base no SNIS 2013, 2013. São Paulo: Instituto Trata Brasil, 2015. 98 p.

KRONEMBERGER, D. Análise dos Impactos na Saúde e no Sistema Único de Saúde Decorrentes de Agravos Relacionados a um Esgotamento Sanitário Inadequado dos 100 Maiores Municípios Brasileiros no Período 2008-2011. Brasil: Instituto Trata Brasil, 2013. 74 p.

LIBÂNIO, P. A. C.; CHERNICHARO, C. A. L.; NASCIMENTO, N. O. A dimensão da qualidade de água: avaliação da relação entre indicadores sociais, de disponibilidade hídrica, de saneamento e de saúde pública. Eng. Sanit. Ambient, v.10, n.3, p.219-228, 2005.

LOPES, F.W.A et al. Bacias hidrográficas como unidade de análise dos processos de urbanização desordenados. O caso da bacia do Córrego do Nado - Belo Horizonte/MG. Geo Uerj, n. especial, p.1985-2002, 2003.

ORGANIZAÇÃO DAS NAÇÕES UNIDAS - ONU. Apesar de progressos, saneamento é 'sonho distante' para milhões de brasileiros. Disponível em: <http://nacoesunidas.org/apesar-deprogressos-saneamento-e-sonho-distante-para-milhoes-de-brasileiros-diz-relatora-da-onu/>. Acesso em: 15 out. 2014.

OPAS - ORGANIZAÇÃO PAN-AMERICANA DA SAÚDE. Cenário do saneamento básico no Brasil: um enfoque sobre as áreas atingidas pela seca e pelo Projeto para Redução da Mortalidade na Infância - PRMI. Brasília: Opas, 1998.

QUEIROZ, J. T. M.; HELLER, L.; SILVA, S. R. Análise da correlação de ocorrência da doença diarreica aguda com a qualidade da água para consumo humano no município de Vitória-ES. Saude Soc, v.18, n.3, p. 479-489, 2009.

RIBEIRÃO DAS NEVES. PREFEITURA MUNICIPAL. Plano diretor de Ribeirão das Neves: diagnóstico e diretrizes básicas. Ribeirão das Neves, 2006. 2 v. Disponível em: <http://rmbh.org.br/ sites/default/files/MZRM.NEVES.PD.vol.II.diagnostico.diretrizes.pdf>. Acesso em: 05 dez. 2014.

SISTEMA NACIONAL DE INFORMAÇÕES SOBRE SANEAMENTO-SNIS. Série Histórica, 2013. Ministério das Cidades. Disponível em: http://app.cidades.gov.br/serieHistorica/> Acesso em: 05 maio 2015.

ZUCARELLI, M.C.; LOPES, F.W.A.; OJIMA, R. Monitoramento das ações em saneamento básico e vulnerabilidade em áreas de risco em Minas Gerais. Conferência Internacional da Rede. vol. 1, pp.113,2010 . 